\title{
Exploration and Research on the Aesthetics and Fashion Trends of Product Design*
}

\author{
Xiaochen Geng \\ Xiamen Academy of Arts and Design, Fuzhou University \\ Postdoctoral Programme of Design Science, Nanjing \\ Normal University \\ Xiamen, China
}

\author{
Zhaojun Wang \\ Xiamen Academy of Arts and Design, Fuzhou University \\ Xiamen, China
}

\begin{abstract}
This paper expounds the relationship between fashion trends and aesthetics and product design. Starting from the epoch characteristic and hierarchy characteristic of aesthetics and fashion trends of product design, the paper expounds that the popularity and aesthetics of product design have different characteristics in different eras and different hierarchies. The paper also discusses the pluralistic phenomenon appearing in the fashion trends and aesthetics of contemporary product design and the consumptive and recreational characteristics that are presented. Finally, this paper advocates designers to grasp the opportunities emerging in the new fashion trends and aesthetics of product design.
\end{abstract}

Keywords—product design; popularity; aesthetics

\section{INTRODUCTION}

The fashion trend is the product of secularization of social life. It is not only the economic foundation of the development of product design, but also the form of activity that constitutes the product design economy. Today's fashion trends are spread mainly on the modern online media, and the aesthetic standard of product design is spread on the network carriers. Aesthetics is the soul of product design. Without aesthetics, there is no life of product design. The fashion trend is the trend of the times that has both the consumptive characteristic and recreational characteristic. In the current era of network information, aesthetic tastes and preferences are more unconventional, aesthetic concepts and aesthetic standards are constantly changing and going through continuous innovations. Product design must be in line with the fashion trends of the times, and it should also pay attention to the hierarchical characteristics of products. Designers should be good at grasping the consumer subjects at all strata and their aesthetic needs. Therefore, designers must make their product design not only lead the aesthetic trend, but also meet the growing aesthetic needs of the public.

* 2014, China National Social Science Fund, project number: 2014CG134, phased result

2015, Chinese Postdoctoral Science Foundation, project number: 2015M570465, phased result

2015, high-level "211" project universities' construction project, Fuzhou University art theory subject support plan, project result.

\section{THE PRESENTATION IN THE TEMPORAL SPIRIT AND THE HIERARCHY}

The aesthetic and fashion trends of product design have certain conceptual characteristics in every era and class, and the characteristics guide the standards of fashion trends. For example, the product design produced in the functionalism of the primitive society, such as: the gravel culture, as well as stone knives, stone axes, etc., they all indicate a kind of power, and the original popular power is formed out of the admiration and yearning for the strong and the survival. "At that time, human beings could not have Bauhaus's design idea. Most of their ideas were formed because they were forced by the environment and developed the concepts. However, their achievements prove that people at this time already had certain aesthetic pursuit and the desire and ability to express the beauty" ${ }^{1}$. After entering the class society, owning the product design became a symbol of power. The aesthetic standard was mixed with the political authority. The product design was mostly from the preferences of the court or royal family. For example, the tin products manufactured in the courts of the Qing Dynasty were very popular at that time. Most of them were manufactured or supervised by the professional staff in the imperial palace. And they would first be popular in the imperial palace and then spread to the society and be popular among the ordinary people. It is a portrayal of the popular mode in feudal society. ${ }^{2}$ With the rise and development of western industrial civilization, product design has changed greatly. The power of currencies has replaced political power and become the dominance of society. After the emergence of the industrial revolution in the western countries in the middle of the 18th century, the class of the frontier reform groups was on the leading position in economic wealth. They guided the forefront of fashion trends, and the product design at this stage became complex and luxurious. The product design under the leading role of the economy had obvious characteristics of "hierarchical autocracy". Therefore, the product design of this period had typical aristocratic

\footnotetext{
Zhuge Kai, "Ten Lectures on Design Art". Shandong Pictoria Publishing House. 2006. p30

"Study on the Art of Tin Products in China", Geng Xiaochen, $\mathrm{PhD}$ thesis, School of Art, Soochow University, 2013
} 
characteristics, forming a "pyramid" type of top-down popularity communication mode. After the 20th century, there had been considerable progress in science and technology. With the rapid development of society, many new product designs in the field of science and technology came into being. "With the invention of electricity, it is possible to produce an electric motor car. And with the magnetic suspension technique, it is possible to produce a magnetically levitated train." 3 In the field of technological development, modern media such as computers, smart phone apps and networks have become popular. The aesthetic taste of the masses began to change. Fashion trends and aesthetics exist in all corners of society, and exist in various groups of society. The main force of modern product design popularity and aesthetic trend no longer has the traditional social upper class color. The "pyramid" type of popularity communication mode has been shaken, and the horizontal communication mode of popularity and aesthetic is particularly prominent in modern society. Here people can see that the fashion trend of modern product design must be forward-looking aesthetic products in all the fine industries of society. The product design without forward-looking aesthetics will be submerged in the wave of modern designs. The popularity and aesthetic trend of modern product design has diminished the hierarchy characteristic and has presented a diversified phenomenon.

\section{THE CONSUMPTION ATTRIBUTE OF AESTHETICS AND FASHION TRENDS OF PRODUCT DESIGN}

The world has already begun to pay attention to China, and the open China has begun to embrace the world. With the current large-scale urbanization process of China, the consumption structure of the villages is changing in the process of villages transforming to cities. The design products in cities are rapidly swarming into villages, and the consumption level has also been unprecedentedly improved. "The market economy puts the production of products into the track of commodity production, and commodity production is aimed at meeting the needs of consumers. Here, consumption activities are the whole process of people to meet their demands, while the demands here refer to the needs which people have the paying ability to meet." ${ }^{\text {"The }}$ popularity and aesthetics of product design have also had new perspectives and have been integrated with the world. Popularity is the economic basis for the development of product design, and aesthetics is the soul and life of product design. The product design produced under the guidance of new aesthetic definition, new popularity concept and new design thinking has great appeal to young people who are seeking new and changing things. Its forms and contents have also been greatly enriched. Product design at this time as a popular fashion consumption concept, it has promoted the principle of happiness to the forefront while being popular among people. The current consumer groups do not actually care about obtaining a design product, they indeed want to get a modern lifestyle through the product. The

Li Chaode, "Design Aesthetics". Anhui Fine Arts Publishing House. 2004. p15. Press. P53. direct way people pursue happiness is the consumption pattern. People can reflect their "identity", "value" and "taste" through the consumption of product design. For example, for the form of identity for consuming various luxury goods, its aesthetic value and willingness to consume play a leading role in the aesthetic and fashion trends of product design. The value of luxury goods is not the exchange value of products, it lies more in satisfying consumers' desire. The fashion and aesthetic trends of product design spread consumption into the focus of life, and make the form of commercial activities of product design penetrate into every field of life and become a social and cultural phenomenon under the leadership of the economic model. This is not just about designing a kind of products, but about designing a consumption relationship. The enjoyment of design products and material consumption are connected, which is the principle of re-combination of the daily experience and practice activities of the public and everyone's own lifestyle, and the development of various social relationships. These are all emphasized in consumption. However, it is necessary to promote the connection of the above things and relax social relationships through the use of product design. That is to say, the consumption mode is a reflection of the structure mode of social consumption of popular and beautiful product designs. When people consume design products, their social relationships are also presented.

The relationship between products and consumption led by consumption patterns has changed, and consumption has become the basis of product design. Some popular panaesthetic contemporary product designs have appeared, such as the development of avant-garde animation products, popular APP, popular apparel, derivative products of films and TV plays, the introduction of new materials and the space design that has emerged as the times require, and the continuously innovative designs of leisure and entertainment places and entertainment facilities. The product design of the new online media has been constantly popularized, making the fashion trends and aesthetic consciousness penetrate into people's living places and daily activities. And the consumption attribute of aesthetics and fashion trends of product design has been fully reflected.

\section{THE ENTERTAINMENT ATtRIBUTE OF THE}

\section{AESTHETICS AND FASHION TRENDS OF PRODUCT DESIGN}

The current popularity trend is no longer the show-off of luxury products by the upper class, and the aesthetic is no longer mixed with politics. The masses' consumption activities tend to happen in the broader cyberspace. Popular consumption mostly occurs in fashionable restaurants, bars, KTV and other public places where there are not obvious boundaries between consumptive activities and other social activities. This kind of consumption-popular product design in daily life begins to show its entertainment attribute. With the advancement of the times, the product design of new online media has been continuously researched and developed, and the public has put forward various requirements for popular product design. The pan-mass network culture is particularly prominent and has gradually 
become the major trend. While the advancement and development of technologies has brought us a new era of information networking, various electronic product manufacturers are trying to fully show their products. At present, Apple's products dominate the current fashion trend, and its form characteristics are not only reflected in the appearance design of the products. Although the appearance design of Iphone, Ipad, Macbook and other products is the simple geometric modernist design, Apple also pays attention to the overall design of products from a holistic perspective, continuously innovating the operating system and interface design while keeping the appearances of products in the same design style, continuously supplying various APP, and fully integrating the entertainment attribute of product design into the operating system. Apple's products with simple and fashionable design style have become the spokesperson of global personal entertainment terminals, and completely lead the entertaining trends of product design in the current era.

At the same time as mobile phones, websites, online apps and offline product consumption venues are in concert with each other, various entertainment places have emerged and can be seen everywhere in this era. In the "restaurants, bars", people can either drink alone or have fun with others; in the "pottery bars", people can get close to the soil, looking for some children's fun; in the "cyber bars", people can communicate with the world. In various popularity and aesthetic trends, I am afraid that no one will deny that various consumption places are the spokesperson of urban popularization and aesthetics. The consumption places are the product of the development of online and offline fashion consumerism of product design. They are consumptive culture based on consumption business value, and the production and dissemination of aesthetic trends are carried out in a popular and fashionable way. With their unique charm, the bars of different styles make people indulge in the wine and the good atmosphere, and indulge in the music and alcohol, and the bars provide people with physiological relaxation and spiritual satisfaction in this way; Internet cafes are everywhere. Consumers can surf the Internet, play games, chat with friends, search for information, and drink coffee, etc. in the Internet cafes. The consumption places have changed the entertainment orientation and consumption methods of the public. The online world has become the mainstream trend and important content of modern life. Consumers can fully entertain and feel the charm of the online world during the process of surfing the Internet. The tea culture in China has a long history. The current terminals are the consumption places. The modern design products such as tea fields, tea bars and tea houses are as elegant and fresh as the tea itself. The tea bars have unique decorative designs and profound cultural deposits. The design of tea bars combines traditional Chinese tea culture with western modern bar culture. It is a masterpiece which integrates Chinese national culture and modern art. It presents a unique leisure style combining Chinese and western styles. 5 Nowadays, there are fashion people who often go to the

Cao Haifeng, Exploration on the "bar culture" under consumerism. "Chongqing Social Science", 2004 pottery bars to feel the soil. They use the most primitive soil to make all kinds of favorite artworks and enjoy the romantic feelings. Coffee, fashion magazines, minimalist modernist furnishings, and a variety of ceramics allow you to feel relaxed while you are close to the soil. Various fashion spaces are filled with different cultural modes and different entertainment ways. They also provide various places for consuming different types of design products, and fashionable new generations are emerging one after another. In order to allow consumers of different aesthetic tastes to find their suitable consumption fields, design products have gradually formed their own unique entertainment culture. As a kind of cutting-edge popular consumer culture, the entertainment attribute of product design has become synonymous with the consumption fields and has become a new symbol of popular consumption and fashion aesthetics. The entertainment attribute of product design makes people enjoy happiness while pursuing happiness. The product design will be more valuable if something more fundamental and deeper in the popular entertainment and aesthetic of product design is combined.

\section{CONCLUSION}

In summary, the popularity and aesthetic trends of product design have contemporary and hierarchical characteristics, and the prevalence and aesthetic trends of contemporary product design have diminished the hierarchical characteristic, presenting a diverse landscape and the consumption attribute and unique entertainment attribute of popularity. Therefore, the designers should conduct calm and rational analyses of the current popular product designs, use the unique aesthetic perspective and the profound Chinese culture for five thousand years, and exert the times forward-looking thinking to make the product design better reflect the aesthetic culture of China and serve the public's life, improving the public's aesthetic cultivation, guiding the fashion trend, and making China's product design lead the new trend of popularity and aesthetic in the world.

\section{REFERENCES}

[1] Li Chaode, "Design Aesthetics". Anhui Fine Arts Publishing House. 2004

[2] Zhuge Kai, "Ten Lectures on Design Art". Shandong Pictorial Publishing House. 2006

[3] Xu Hengchun, "Design Art Aesthetics". Tsinghua University Press. 1960

[4] Cao Haifeng, Exploration on the "bar culture" under consumerism. "Chongqing Social Science", 2004

[5] Geng Xiaochen, "Study on the Art of Tin Products in China", PhD thesis, School of Art, Soochow University, 2013 